Alienation in a Four Factor World*

\author{
Daniel Silver \\ The University of Toronto
}

[Forthcoming in The Journal for the Theory of Social Behavior]

*Daniel Silver, Department of Sociology, University of Toronto, 725 Spadina Ave, Toronto, ON M5S 2J4, dsilver@utsc.utoronto.ca 


\title{
Alienation in a Four Factor World
}

\begin{abstract}
This paper aims to reconstruct the concept of alienation as a live topic for active social theorizing. Joining Marxian and Simmelian ideas, it provides a multi-dimensional, formal, and synthetic theory of alienation. The paper develops a set of theoretical tools for articulating formal elements of action that make alienation possible, without giving conceptual priority to alienation in the sphere of production, or within that sphere to the alienation of labor. These tools make it possible to derive classical notions of alienation as specific, contingent combinations of multiple elements, theorizing them as concrete socio-historical configurations of a broader universe of possibilities. They also organize systematic reflection on various forms and relations of alienation; not only those between for instance labor and capital, but also among all four factors of production: land, labor, capital, and entrepreneurship. The paper accordingly develops an original, multi-dimensional theorization of alienation for a complex, pluralistic world.
\end{abstract}

Keywords: alienation, Simmel, Marx, theory, action theory,

This paper aims to reconstruct the concept of alienation as a live topic for active social theorizing. ${ }^{1}$ It seeks to recombine and expand elements of classical alienation theory to produce a more multi-dimensional, formal, and comprehensive theory of alienation, geared toward the pluralistic contemporary social world. While classical Marxian alienation theory provides important resources for this endeavor, it is also limited in crucial respects. Most notably its essentialism and reliance on the logic of dichotomies restrict its adaptability to the present. To develop a new conceptualization, this paper brings certain Simmelian sensibilities to bear on the Marxian formulation, such as pluralism and perspectivism, while drawing from Jaeggi's (2014) path-breaking philosophical work.

Alienation is a crucial term in the social theoretical lexicon that has done important work and can continue to do so, if it can be refashioned into a multi-dimensional tool for understanding and analyzing our pluralistic contemporary scene. Though in recent decades alienation theory has been relatively marginalized among social theorists, worries about 
alienation of some form or another persist, under various guises. We hear concerns about how contemporary flexible 'knowledge work' promotes 'the corrosion of character' (Sennett, 2011) and a split between 'thinking and doing' (Crawford, 2009); how homogeneous urban environments produce experiences of 'placelessness' (Relph, 2008); how fragmenting communities heighten political disaffection (Alexander, 2006); how 'uncertainty' and a 'more knowledgeable public' yield a 'malaise of modernity' generating widespread 'disenchantment' with institutions (Guppy and Davies, 1999); and much more. There now exists for example a robust and fast-growing interdisciplinary discourse on boredom (Gardiner and Haladyn, 2016).

Even as such expressions and observations of malaise persist, alienation theory has receded from the center of sociological theorizing. This is in part because sociological theorists have not developed a suitably flexible conception of alienation, one capable of dealing with these myriad, contingent alienations. This paper aims to develop such a conception of alienation, grounded in an acknowledgment of contingency and pluralism: there is no single ultimate source of alienation, and alienation may emerge through multiple combinations of diverse factors.

To develop this model, the paper proceeds in four main sections. The first briefly summarizes the vicissitudes of alienation theory, suggesting that in addition to considering contextual factors feeding into its waxing and waning, it is worth reengaging the inner assumptions and concepts of traditional alienation theory itself that have restricted its currency. The second section outlines three general principles for moving forward, theoretically: formalize substantive concepts to shift from 'what' questions about the ultimate nature of human being and motivation to 'how' questions about ways of acting that may be more or less alienated regardless of their specific substantive content; expand the scope of alienation theory to make it more multidimensional - in the sphere of production to incorporate more factors of production (beyond 
labor and capital), and in general action theory to incorporate more dimensions of action (beyond personal effort and utilitarian calculations); bring key elements of the Marxian and Simmelian approaches to alienation into productive dialog, in particular joining Marxian emphasis on integration and separation, relations between individuals and groups, and production, with Simmelian emphasis on growth and ossification, relations between subjects and objects, and a non-reductive pluralism.

The third section puts these principles to theoretical work, building from the classical Marxian formulation. The aim here is not so much to produce a new and finally correct exegesis of Marx's ideas but to take well-known Marxian concepts as vehicles for illustrating the theoretical fertility of the approach developed in the previous sections. Accordingly, this section reformulates some core Marxian concepts central to the tradition of alienation theory as forms of self-world relationships; expands the purview of alienation theory from two to four factors of production; and synthesizes the concepts of integration and growth to generate four analytical dimensions of action that may become alienated. With these conceptual tools, various forms of alienation may be derived, such as powerlessness, indifference, disorientation, and reification. The fourth section introduces a diagrammatic device - 'the wheel of alienation' - for systematically and experimentally theorizing about alienation from multiple perspectives and at various levels of generality so as to map out the contours of its possibility space. The conclusion reflects on the implications of this approach for building an agenda for advancing alienation theory and research.

\section{The vicissitudes of alienation theory, a brief sketch}


Alienation in various guises seems to always be with us. But alienation theory waxes and wanes. Alienation was a central theme for many of the giants of modern social thought.

Rousseau charted its contours, even if he did not use the term. Hegel used the concept explicitly, and Feuerbach integrated it into his religious anthropology. Marx produced the foundational statement for modern social theory in the Economic and Philosophical Manuscripts of 1844, followed by Simmel in The Philosophy of Money. Durkheim and Weber discussed similar phenomena under the headings of disenchantment and anomie. Post-Marxian critical theorists such as Lukacs, Adorno, and Horkheimer famously carried forward the tradition of alienation theory, as did Parsons and Merton. Alienation was also a major theme in existentialism, often with Kierkegaard as classical inspiration, and among conservative and communitarian social critics (cf. Oldenquist, 1992).

The theme of alienation was also vigorously pursued in mainstream empirical sociology in the 1960s and 1970s, led by Melvin Seeman (Seeman, 1957, 1967, 1975, 1983). During this period, theoretical and methodological discussions of alienation within the discipline of sociology became highly elaborated (e.g. Geyer and Schweitzer, 1981; Israel, 1971; Ollman, 1976; Schacht, 1971; see also Debord, 1994; Lefebvre, 1968). These discussions sometimes became flashpoints for broader debates, for instance about positivism vs. critical social theory (e.g. Harvey et al., 1983).

Yet by and large, since the early 1980s alienation has become a less central theme among sociologists and social theorists. ${ }^{2}$ In 1983 , Seeman wrote 'the analytic attraction of the concept of alienation seems similarly to have been exhausted... In fact, one senses a certain antiquated air surrounding its current use' (Seeman, 1983, p. 171). This declining centrality was not restricted to the more positivist and social-psychological stream of research that Seeman had pioneered. 
Jaeggi noted a similar shift in the continental critical theory tradition, 'Not only has alienation nearly disappeared from today's philosophical literature, it also has hardly any place any longer in the vocabulary of contemporary cultural critique' (Jaeggi, 2014, p. ix). To be sure, some have kept the flame alive at the margins of the discipline (e.g. Geyer and Heinz, 1992; Langman and Kalekin-Fishman, 2009, 2006), but in general it seems clear that alienation has been sidelined as a topic for creative theorizing and empirical research. Indeed, Yuill (2011) found that just three articles on alienation had been published between 1978 and 2011 in three leading US journals (Yuill, 2011, p. 109), whereas in previous years alienation had been a major topic in such venues. Similarly, the British Journal of Sociology has not published an article with 'alienation' in its title since 1979.

Why did alienation theory wane? There is no single clear answer. Yuill (2011) and Jaeggi (2014) suggest several plausible factors. Given the generally Marxian project with which alienation theory has been traditionally associated, the various political setbacks Marxism suffered since the 1980s likely played a role. Within Marxism, Althusserian anti-humanism and analytical Marxists sidelined existentialist themes. Postmodernists (e.g. Baudrillard, 1994) attacked the idea of an underlying human essence that could be alienated by certain working conditions (cf. Callinicos, 2006). Heavy industry declined, post-industrialism and consumerism grew. Alienation theory seemed geared to the former, while the latter issued in notions such as flows (Urry, 2000) and networks (Castells, 1996). At the same time, the study of work increasingly migrated from sociology departments to business schools, where research examined topics such as how to manage stress and balance work and life, rather than pushing to deeper forces that generate stressful or imbalanced lives in the first place (Strangleman, 2005). 
These and possibly other factors may have coalesced to push alienation theory into the background. But this does not mean alienation itself disappeared. Rising inequality, routinized workplaces, empty consumerism, social isolation, the 'corrosion of character' (Sennett, 2011), homogenous places, political polarization, institutional cynicism, hyper-cognitive knowledge work, and similar phenomena have been highlighted by authors seeking to demonstrate a 'hidden continuity' with alienation of yore (Jaeggi 2014; Langman and Kalekin-Fishman, 2009; Schacht, 1994, p. 2) and spark renewed intellectual interest in the topic.

Contextual factors may well play a role in the waning and waxing and waning of alienation theory. For sociological theory, however, it is worth considering the matter from a point of view internal to alienation theory itself. Indeed, alienation theory became rather moribund after its mid-century zenith. Seeman's positivist stream was mostly atheoretical from the start, concerned with assembling and distilling common uses of the term to build analytical dimensions (powerlessness, meaninglessness, isolation, etc.) and empirical indexes, the specific formulations of which had dubious connection to their theoretical source material (Harvey et al., 1983). The theoretical aspect of this stream was largely devoted to seeking abstract covering definitions to guide empirical research (e.g. Fischer, 1976), rather than to deriving analytical concepts from a coherent model of action. For its part, as work in heavy industry became less widespread, the critical theory stream primarily sought to extend classical Marxian alienation critiques of modern society to new arenas, focusing on technology, consumerism, and identity politics (Erickson, 1986; Langman and Kalekin-Fishman, 2009). Marx was taken for granted, as were the basic anthropological and action-theoretical assumptions on which the classical Marxian theory of alienation was based. 
For these sorts of reasons, the most thoroughgoing recent philosophical treatment of alienation aims 'neither to update the problem of alienation by looking at its contemporary manifestations nor to discuss alienation in a way that remains within the confines of an already defined theoretical framework' (Jaeggi, 2014; p. xx). To reconstruct a moribund concept it is not enough to simply dust it off and put it back to work: a new application requires a new

articulation. Yet neither should we abandon classical insights, which have profoundly plumbed the depths and dynamics of the topic. This paper pursues a pragmatic middle course, aimed at transforming yet preserving classical meanings by engaging them as living occasions for creative theorizing and model building rather than as fixed orthodoxy or established conventions, to be merely updated or mined.

\section{Toward a conceptual reconstruction: formal, multi-dimensional, dialogical}

As a first step toward this re-articulation, consider three general orienting principles: formality, multi-dimensionality, and dialogical cross-fertilization.

Formality. Jaeggi (2014) argues that one of the major stumbling blocks of traditional alienation theory was its reliance on a substantive conception of human nature. In the Marxian stream, this conception was associated with an anthropology of labor, which continued in prominent mainstream sociological research. For example, in his 1985 Presidential Address to the American Sociological Association on 'Work and Alienation,' Kai Erickson urged sociologists to reengage with Marxian alienation theory.

'the producer, then, and the thing he produces, are of the same flesh. Or at least that is the way nature intended it to be. In the age of industrialization and capitalism, however...developments have conspired to disturb that natural arrangement' (Erickson, 1986, p. 1). 
This is a striking example of how conceptual pressure built into traditional alienation theory pushes one in a teleological direction: to criticize some state as alienating can seem to require envisioning such a state as a departure from some natural arrangement, and to conceive nature as an entity capable of intentions. While the external and contextual factors cited above likely played some role in the decline of alienation theory, reliance on an outmoded teleological and essentialist anthropology poses a distinctively theoretical obstacle to the on-going relevance of the concept.

A theoretical problem requires a theoretical solution. Jaeggi identifies a number of theoretical problems that this sort of essentialism produces, and points toward some solutions (see especially Jaeggi 2014, pp. 2, 15, 27; for critiques of essentialism in general, see Emirbayer, 1987; Fuchs, 2009). For instance, it assumes we know a priori what humans' genuine or ultimate needs are, such that certain social relationships may distort or thwart them. It also assumes a self with a transparent, unified, and self-sufficient inner life, which is then blocked from being realized by an external agency. Learning and growth through experiences and interchanges with the world and others become incomprehensible as anything other than inherently alienating, as do the complex multi-dimensional selves that characterize complex social orders.

Drawing from Ernst Tugendhat and writing in a broadly Kantian vein, Jaeggi argues that alienation theory can overcome its essentialist impulses by building from a formal theory of action (see also Rae, 2010). 'How, not what' becomes the centerpiece. That is, instead of asking what people truly want or need, we ask about the formal conditions under which action is possible. For instance, to be able to act, an agent must have some sort of command or disposal over her will. Arrangements (such as compulsion) that distort this capacity and its attendant conditions - such as the capacity to creatively incorporate aspects of the environment or learn 
from past experiences - may be deemed alienating without any substantive implications about what, specifically, people should be striving for, or what 'nature' intends them to be striving for.

Such an account is formal and immanent. It is formal because it concerns the 'how' not the 'what' of action, and involves identifying not natural or essential goals or aims but rather certain ways of relating in one's actions to oneself and the world. It is immanent because it locates the conditions of successful action in action itself. Failed or debilitated action is action that somehow ceases to be action, in for instance loss of meaningful orientation and commitment, the ability to adapt to on-going situations, or take on the role of others. ${ }^{3}$ 'Instances of alienation can be understood as obstructions of volition and thereby - formulated more generally - as obstructions in the relations individuals have to themselves and the world' (Jaeggi, 2014, p. 34). Accordingly, building on Jaeggi's insights implies that a first guiding principle for reconstructing a sociological theory of alienation is to formalize its central concepts and ground them in conditions immanent to action theory.

Multi-dimensionality. The precise scope of Marx's theory of alienation has always been difficult to determine. On one hand, Marx clearly has the industrial workplace in mind, and within it, the alienation of labor at the hands of capitalists. On the other, owing to his Hegelian and Feuerbachian heritage, Marx takes a much more expansive view, associating alienation with the general dynamic whereby human creations take on a life of their own, and control the fates of their creators. This latter point of view carries the process of alienation out of the workplace and into theology and culture. It resonates more with Simmel's overall orientation (Arditi, 1996; Canto-Mila, 2015), and has been an inspiration for post-Marxian writers seeking to extend the notion of alienation into areas such as culture and consumption (Langman 2004). 
Yet this expansive impulse can be difficult to carry out because it can clash with another Marxian tendency: dichotomization (Baldamus, 1976; Parsons, 1967). This tendency is most evident in Marx's reduction of the field of production to a two-way conflict between labor and capital (discussed in more detail below), explicitly pushing into the background other factors of production - most notably land - that his predecessors such as Smith and Ricardo had foregrounded. The logic of dichotomies make it difficult to countenance processes and relationships that fall outside them.

For alienation theory, overcoming the logic of dichotomies for a more multi-dimensional approach has a twofold implication. First it means not restricting analysis of alienation within the sphere of production to the confrontation between capital and labor. Second, it is necessary to carry this same spirit of multi-dimensionality into the more general and formal theory of action on which alienation theory relies. Here the general point is less about the specific dimensions and more about the theoretical value of multi-dimensionality. By abandoning the logic of dichotomies we gain a theoretical foothold for expanding the scope of the alienation concept beyond the narrow confines of labor and capital.

Dialogical cross-fertilization. Marx's great humanistic statement about the alienation of labor has provided the platform for the vast bulk of alienation theory, and any fresh theory of alienation must start here. Yet here, as in other cases (Levine, 1995), new theoretical vistas may be opened through placing classical theories into productive dialogue with one another. Georg Simmel's reflections on alienation, primarily in his Philosophy of Money but also in his later work (e.g. 'The Concept and Tragedy of Culture,' 'The Conflict in Culture,' and The View of Life), provide a valuable fund of ideas that may enrich the Marxian tradition. 
Poggi (1993, ch. 7) provides perhaps the most incisive analysis of the overlaps and divergences between Marx and Simmel's conceptions of alienation. Both share the major topoi in alienation discussions: the autonomization of human products (taking on a life of their own, frustrating the wills of their creators) and the metaphor of inversion: inversion of means and ends, subjects and objects, causes and effects.

Yet Marx and Simmel differ in key areas of their alienation theories. Marx seems to tie alienation as such to the socio-historical moment of capitalism, and views a post-capitalist world as a world without alienation; for Simmel alienation is inherent to the human condition, even if it is intensified in a money economy. For Marx alienation tends to be clear-cut, as producers either expropriate workers or they do not; for Simmel alienation is more ambiguous; it is always possible, but never necessary - a visit to the theatre may be alienating, but it need not. Marx highlighted alienation in relations between persons and groups (primarily workers and capitalists), Simmel looked to subjects losing touch with objects (primarily of cultivation). Marx tended to derive other forms of alienation from economic alienation, Simmel refused to give economic affairs conceptual priority. Where they did highlight alienation in the economic domain, Marx highlighted production, whereas Simmel featured exchange. Marx's theory of alienation was part of a prophetic visionary revolutionary program geared toward a society free of alienation; Simmel prized more individualistic values of scholarly attainment, intellectual integrity, and aesthetic sensitivity, and saw alienation as a challenge to persons' abilities to comprehend and appreciate their existences. Marx tended to diagnose alienation as a symptom of some kind of disintegration or separation (Schacht, 1994, p. 38); Simmel featured obstacles to creativity, vitality, and growth (Levine, 2004). 
Rather than treat these differences as a contest for singular theoretical supremacy, we can take them as pointing toward opportunities for fruitful theoretical cross-fertilization (Camic and Joas, 2004). Particularly promising are aspects of the Simmelian conception that aid in reimagining the Marxian framework in more formal and multi-dimensional terms. ${ }^{4}$ Here Simmel's non-reductive pluralism and perspectivism are crucial (Levine, 1995, p. 304). These orienting principles enable us to avoid essentialism by approaching alienation from multiple points of view without prioritizing any one over the others - for instance, from a pluralistic point of view, as we will see, alienation occurs not only in tensions between capital and labor, but also in tensions between multiple factors of production: capital-land, labor-entrepreneurship, laborland, and so on. Equally promising is the prospect of joining the Marxian focus on inter-group processes and the Simmelian concern with objects becoming closed off from subjects, and integrating alienation as separation and disintegration with alienation as the loss of vitality and creativity.

\section{Building a conceptual took-kit for alienation theory}

With these orienting principles in mind, let us return to Marx's classical statement as a starting point for applying them. Consider first Marx's famous discussion of alienation as a fourfold process: under capitalist conditions, workers are alienated from their products, from the labor process, from their fellows, and from their species being. The general thrust of Marx's account is well known and need not concern us here. The value of the Marxian categories in the present context comes in providing widely shared terms for putting to theoretical work the orientating principles elaborated above. 
Marx's four-fold alienation: from what to how. Marx's portrait of the alienated worker is closely tied to industrial conditions and to his anthropology of labor, as discussed above. But it is not difficult to see in his four-fold picture of the alienation of labor the seeds of a more formal account of self-world relationships not tied to any specific content. That is, in the spirit of Jaeggi, Tugendhat, and Rae, we can convert Marx's four-fold alienation from a theory of what alienation consists in substantively (its essential content) to a theory of how alienation disturbs ways of relating self and world (its form).

Table 1 summarizes a recasting of Marx's four-fold alienation in formal terms.

\begin{tabular}{|l|l|l|}
\hline \multicolumn{2}{|l|}{ Table 1. Marx's four-fold alienation recast as forms of self-world relations } \\
\hline & \multicolumn{2}{|l|}{ Self's alienation from... } \\
\hline Agentic objects & Self-self & process \\
\cline { 2 - 3 } & Self-other & fellows \\
\hline Non-agentic objects & Self-artifact & product \\
\cline { 2 - 3 } & Self-environment & species-being \\
\hline
\end{tabular}

The far-right column lists Marx's basic categories of alienation: alienation from process, fellows, product, and species-being. The left column organizes these into two major groups, according to whether they are oriented toward agentic objects. Marx's categories seem to be implicitly structured along these lines: workers become alienated from agentic objects, namely their own activity and that of other workers, but they also become alienated from non-agentic objects, namely their products and species-being. 
The middle column summarizes this pattern in formal terms. 'Self' is the common thread to all forms of alienation, whatever the object. Alienation always involves some failure or disturbance of a self's capacity to lead its own life (Jaeggi, 2014, p. 22). Some component in an action process becomes inaccessible and alien, an impediment rather than stimulus, and the loss of power to act is intertwined with an evacuation of meaning.

But 'leading a life' involves the self in a number of relations. First and foremost, with itself, but also with other selves, with artifacts that extend its capacities to act in the world, and with a facilitative environment. For instance, a self that is alienated from itself has become rigid, me but not me, an alien force that seems to push me to do and be things that are not 'really' me whatever that happens to be. A self that has become alienated from others has lost the desire for their desire and recognition, they become tools to be used or manipulated or mere obstacles rather than sources of mutual affirmation and esteem and respect. A self that has become alienated from its artifacts has lost touch with them as extensions and enhancements of its capacities to act beyond itself in the world, they become instead impediments and frustrations. A self that has become alienated from its environment does not experience it as a world that demands and sustains growth in perceptiveness, intelligence, sympathy, and creativity - a loving world (cf. Lear, 1990) - but rather as a disorienting field of enmity, envy, destructiveness, and, perhaps worst of all, dulling indifference. Thus Marx's conceptualization has the seeds of a more formal theory of alienation grounded in diverse ways in which action relates self to world. ${ }^{5}$ A four-factor world. To be sure, shifting from Marx's vivid concepts to more formal terms can seem to take some of the blood out of a conceptual scheme rooted in a concrete image of the industrial worker confronting the rapacious boss. But this loss is compensated by the theoretical gains it generates, in opening up alienation theory to a wider range of potential 
objects and grounding this transfer in the common forms of action and relation they may exhibit, rather than in sharing a set of substantive grievances necessarily similar in content to those Marx found.

Nevertheless, surely part of the power of Marx's original formulation is that he situated his humanistic portrayal of the self-denied-itself in the context of concrete groups and agents interacting. Yet in this portrayal Marx largely restricted his vision to the confrontation between capital and labor. A contemporary theory of alienation must widen the lens while retaining the capacity to apply to concrete and recognizable agents. To do this, let us stay with Marx in the sphere of production and turn to the question of what generic forms of activity production involves, and how those forms may become alienating.

Marx's great predecessors, Adam Smith and David Ricardo, typically spoke of three not two factors of production: land, labor, and capital. They associated each with distinct types of proceeds - land with rent, labor with wages, capital with profit. They also associated each factor with distinct social types: land with aristocrats and peasants, labor with wage workers, capital with industrialists.

Smith and Ricardo's accounts of the distinct contribution of each factor to productive work are full of puzzles and complexities (cf. Gee, 1981; Lackman, 1976), but the underlying intuitions are clear enough. Work performed by more skilled, industrious, and energetic workers will be better than work performed by lower quality workers; this is the contribution of labor. Work performed with bigger and better tools will be more productive than work without such tools; this is the contribution of capital. Work performed in a fertile environment will be more productive than work performed in a barren one; this is the contribution of land. Early formulations tended to treat land in narrow agricultural terms, but later theorists, especially 
Alfred Marshall and then following him Talcott Parsons and Neil Smelser (2005), treated the 'fertility' of land in much broader cultural terms, as environmental situations that enhance the productivity and abilities of those who enter into them (see also Mei, 2017). Later theorists most notably Marshall and Joseph Schumpeter - added a fourth factor, entrepreneurship, which operates according to a similar logic. Work performed with the aid of entrepreneurial intelligence and creativity will be more innovative and adaptive than work undertaken with a less creative spirit.

Marx studied Smith and Ricardo in great depth, and was well aware of their theories of land and rent. He worked in his later years to integrate a theory of land and rent into Capital, but never seems to have been able to do so in a satisfactory way. Geographers, most notably David Harvey in Limits to Capital, have endeavored to reconstruct and extend Marx's thoughts on the topic, but even Harvey calls Marx's ideas 'tentative thoughts set down in the process of discovery' (Harvey, 1982, p. 330). ${ }^{6}$ Marx's early statement on alienation directly follows a summary of theories of rent, the outcome of which was to assimilate land into capital. 'The final consequence is thus the abolition of the distinction between capitalist and landowner, so that there remain altogether only two classes of the population - the working class and the class of capitalists' (Marx, 1959, p. 25).

Marx had any number of reasons for making this reduction of a complex field to two principal antagonists. Politically, he wanted to 'sharpen the contradictions' of modernity to a fever pitch, where a final confrontation of the latent struggle defining all hitherto history could come to the fore. Philosophically, the dialectical-Hegelian structure of his argument requires two opposing polarities that clash before they are reconciled at a higher level (Kolakowski, 1978, pp. 130, 152). And from an economic-technological point of view, Marx arguably believed that 
capital was well on its way to absorbing other factors of production such as land, so that if land (and its characteristic social types, aristocrats and peasants) appeared to be a separate dimension in economic life, that was only because capital had been less extensively applied to agriculture (Marx, 1967, pp. 760, 765; see also Howard and King, 1985, pp. 147-148).

A singular focus on the stark conflict between capital and labor may have been appropriate in Marx's time, but not today. We live in a multiple factor world that accordingly may generate multiple forms of alienation. The economic importance of place has only grown. Where people work is a crucial factor in their productivity and success (Currid, 2007; Glaeser, 2011; Harvey, 2009; Moretti, 2012). Critical geographers are giving renewed attention to the fact that 'land is not the same as capital but has unique attributes as a factor of production which require a separate theorization' (Ward and Aalbers, 2016; see also Mei, 2017), just as urban political economists had previously recognized that capitalists, land owners and developers, and workers often represent distinct interests (Logan and Molotch, 1987). The greatest driver of inequality in recent decades is not the wealth of industrial capitalists but urban land prices (Rognlie, 2014). Entrepreneurship has become just as central. The creative class is ascendant in post-industrial societies (Florida, 2004; Bell, 1976), and does not necessarily align politically with traditional economic elites (Markusen, 2006). Creativity has been institutionalized and internalized as a vital personal, social and economic quality, such that the contemporary means of production are also lodged in the creative intelligence, analytical acumen, and aesthetic sophistication that generate new and interesting products (Lloyd, 2010; Reich, 2002).

The importance of all four factors to contemporary work is evident. Less noted, though, is the clear implication of this importance for alienation theory. Since work involves multiple factors of production, they all may be alienated by and from one another. A multi-dimensional 
theory of alienation is therefore required. For instance, just as places can enhance one's abilities, there can be place alienation: living in a sterile environment that dulls one's productivity or creativity or even more profoundly does not permit one to become the kind of person one has the potential to be. Lefebvre pioneered theories of place alienation, but as Yuill (2011, p. 107) notes 'the late translation of his work into English has, however, limited his influence outside France until fairly recently.' For their part, phenomenological geographers have documented place alienation as the opposite of the 'sense of place' (Relph, 2008). Likewise, just as there can be place alienation, observers of the contemporary workplace have remarked upon what we might call entrepreneurial alienation, for example when the free-flow of ideas comes to be experienced as a debilitating split between thinking and doing, head and hand (Crawford, 2009). In these and other ways alienation is not only the province of labour's struggle with capital but a possibility for all participants in the productive process.

From types to dimensions. Building conceptual infrastructure for systematically organizing reflection on multiple possible forms of alienation among all four factors is the major goal of this paper. To do so, however, it is necessary to move from treating them as types to treating them as analytical dimensions. The theoretical advantage of analytical dimensions over type concepts is additional scope, precision, and flexibility that permits the discernment of unity amidst diversity, continuity amidst change, configurations out of combinations. This was one of Parsons' major critiques of Max Weber in The Structure of Social Action (1949): 'The Protestant Ethic' identifies a narrowly circumscribed historical social type. But analytical dimensions, such as 'commitment to work,' can travel, and be found in various degrees in many persons, groups, and situations. Marshall made a similar point about rent. One of his key conceptual innovations was to treat rent as an analytical element present in all objects of value, rather than as strictly 
identical with the physical earth: 'even the rent of land is seen, not as a thing by itself, but as the leading species of a large genus' (Marshall, 1892).

A similar move helps expand the scope of alienation theory beyond the sphere of production to lay the ground for a more general model of alienation. The four factors are specifications of formal analytical elements present in all activity, and to varying degrees in individuals and groups. That dimension of action that arises from its environmental situatedness is in the sphere of production its 'land' component, and where this component predominates, we may observe in greater degrees a 'landed' temperament, traditionally associated with aristocrats and peasants but perhaps accentuated in different groups today. In the domain of production, entrepreneurship identifies the capacity for creative problem solving, and individuals or groups where this aspect predominates are more entrepreneurial. Likewise, the 'capitalist' moment in production involves a generic form of action: accumulating instruments or means of action and deploying them to enhance the capacity to achieve one's ends. Finally, the 'laborious' aspect of work is a specific form of a general dimension of action: the motivational effort one pours into an activity (Baldamus, 2013). All four may be present in the same individual, even if the distribution across individuals and groups varies.

Shifting from types to dimensions places alienation theory at a higher level of generality that embodies the injunction, outlined above, to move from 'what' to 'how.' Capital, labor, land, and entrepreneurship become specific incarnations within the sphere of production of more formal ways of acting not necessarily geared toward a specific substantive set of goals or ideal states. These capacities may operate in or beyond the workplace, and by articulating their potential combinations and clashes we can both abandon traditional essentialist assumptions of alienation theory and produce a more general theory capable of elaborating the dynamics of 
alienation in production as specifications of a more general problematic that may apply to other domains.

The fusion of integration and growth. The discussion so far has developed concepts for articulating a) ways of relating to oneself and to one's world that may be realized or disturbed and b) formal aspects or components of an action process that may become alienated by and from one another, namely, labor (effort), capital (means), land (environment), entrepreneurship (creativity). To be able to combine these into a single synthetic model, another step is necessary. We need to examine what it means to be alienated.

The traditional Marxian framework tends to highlight alienation as disintegration or separation (Fischer, 1976; Schacht, 1994, p. 38). In order to realize itself, the self needs to identify with its products, its activity, its fellows, and its environment. When the self is separated and disintegrated from these, they come to stand before it not as aspects of itself or essential aids to realizing its capacities. Instead they become foreign entities. Thus disintegration makes the self a stranger to itself.

But integration and disintegration are not enough on their own to comprehend alienation. One can be separated from something without being alienated from it. Likewise, integration can itself be a source of alienation: one loses oneself in the accepted conventions of 'what one does', a particular form of alienation highlighted by Martin Heidegger in his analysis of 'das Man' in Being and Time. Hence Rae (2010) points to the distinction between antagonistic and integrative authenticity, where the former involves taking a critical stand on taken-for-granted customs and thought-patterns. At the same time, hyper-criticism can leave one unmoored and adrift, without the anchors needed to realize oneself in effective worldly actions, a form of alienation critique rootlessness - that tends to be associated with conservative critiques of modern society. 
To supplement the 'integrationist' conception of alienation we can turn to Simmel. Though Simmel like Marx did emphasize separation and disconnection as crucial to alienation, Simmel more prominently featured growth and creativity, especially in his later vitalistic writings. ${ }^{7}$ Expansive and creative life over and against rigid form became the major 'conflict in culture' (Simmel, 1968). In this conception, life is both 'more life' and 'more than life' (Simmel, 2010). Life as 'more life' means that life is growth and expansion; life as 'more than life' means that life is creative self-transcendence, reaching out to generate new forms of living, but never being completely satisfied by them. ${ }^{8}$ Where life contracts, shrinks, and ceases to expand or overcome its current forms, it is dead or dying. Accordingly, the self that becomes stuck, incapable of growth and creative self-transformation, has lost touch with itself as part of a vital living process. Thus if integration and growth are crucial aspects of what it means for a self to actively realize itself in the world, disintegration and stultification are the seeds of alienation.

Because integration and growth are both simultaneously at stake in self-realization and alienation, it is necessary to treat them as interacting rather than atomistically independent processes. The realization of self and its alienating disturbance occurs at the intersection of growth and integration. We can conceptualize this synthesis with the help of a four-fold table, as in Table 2. 


\begin{tabular}{|c|c|c|}
\hline Table 2. Synthesizing integration and growth & Receptive \\
\hline Integration & Active & Effort/Labor, indifference \\
\hline $\begin{array}{c}\text { More } \\
\text { (expanding) }\end{array}$ & $\begin{array}{c}\text { Means/Capital, } \\
\text { disempowerment }\end{array}$ \\
\hline $\begin{array}{c}\text { More-than } \\
\text { (self-transcending) }\end{array}$ & Creativity/Entrepreneurship, reification & $\begin{array}{c}\text { Environment/Land, } \\
\text { disorientation }\end{array}$ \\
\hline
\end{tabular}

Table 2 crosses growth and integration to produce four ways they can intersect, both at the level of general action theory and in the domain of production. Following Simmel, it divides 'growth' into two: 'more' and 'more-than,' or the expansive and self-transcending aspects of vital growth. Following Simmel again (Simmel, 1997), it divides 'integration' into two, active and receptive. The active side of integration refers to what Simmel called 'subjective culture': reaching out toward an object and striving to identify with it. The receptive side refers to what Simmel called 'objective culture': the experience of objects as open to or closed off from such striving - for instance a fitting tool that is ready to be put to work, asks to be handled, in contrast to one that seems unsuited to the task at hand, or a collaborator who is open and responsive to one's thoughts and desire.

The four inner cells show the intersections of these aspects of growth and integration. They are populated with the same four factors discussed above, with the first term referring to formal dimensions of action and the second to the sphere of production: effort/labor, means/capital, creativity/entrepreneurship, and environment/land. Effort lies at the intersection of active integration and expansive growth, striving to pour energy outward. This is the 'laborious' dimension of production, as we actively strive to maintain motivation and expand the energy 
with which we work. Means of action by contrast are the receptive side of expansive life, the tools capable of receiving our energies and heightening their power. This is the 'capitalistic' dimension of production, the accumulation of tools and infrastructure - the means of production - that empower human productivity to continually grow, engendering more work with less effort. Creativity marks the active side of self-transcendence, striving to overcome current forms of thought and action; in the sphere of production, this is the 'entrepreneurial' dimension. Finally, the environment is the receptive aspect of self-transcendence, the world beyond the self that draws one out of oneself, demands that one develop abilities that one would not be able to develop on one's own. In the sphere of production, this is 'land,' the external environment that enables one to do and be things that one could not do and be elsewhere (Mei, 2017).

Synthesizing integration and growth in this way reveals something that might not have been otherwise apparent: the four factors comprise four ways of fusing growth and integration, and therefore indicate four sources of alienation. These are shown in italics in Table 2. The collapse of effort is the self's loss of the capacity to maintain active energy for its projects, indifference. The breakdown of creativity is the incapacity to continually transform and reconstruct, reification. To be cut off from means of action diminishes the self's ability to exercise control over its environment, disempowerment. An evacuated environment that fails to offer meaningful direction generates disorientation. While indifference and reification emerge primarily in a self's relation to itself, disempowerment and disorientation emerge in relation to the world.

Fusing integration and growth not only joins major ideas of Marx and Simmel central to the tradition of alienation theory, it provides a framework from which we can derive - rather than merely list - core concepts that have often been used to specify the qualitative experience of 
alienation. This is a quite remarkable and surprising result, not at all obvious at the outset. It reveals simple structural principles - growth and integration - at work in the rich, complex, and wide-ranging verbal formulations that mark phenomenological discourse about alienation, retaining their specifics while illuminating how they emerge at the intersection of common basic processes. Even Jaeggi's penetrating analysis tends to move through various alienation themes one after the other. Yet as a synthesis of growth and integration, disparate descriptions of topics such as reification or disempowerment become intelligible as specific manifestations in a general model. Fusing insights from Marx and Simmel illuminates these processes in ways that neither could alone.

\section{The Wheel of Alienation}

The aim of the preceding sections was to build up a conceptual toolkit for alienation theory. We now have a number of tools in hand: formal relations of self and world; four factors; integration, growth, and their intersection. Throughout we have stressed connections between these general tools and their Marxian specifications. The goal is not to replace or re-interpret Marx's texts, but to build a theoretical infrastructure in which core alienation concepts may be derived as particular combinations among others. In this way we preserve the classical Marxian application as a special case of a more general multi-dimensional model for describing many other modes of alienation that continue to confront us, but for which we lack - and sorely need a common vocabulary that reveals their interconnections, similarities, and differences. This in turn paves the way for empirical questions about where and why one combination rather than another occurs, and how they have changed. 


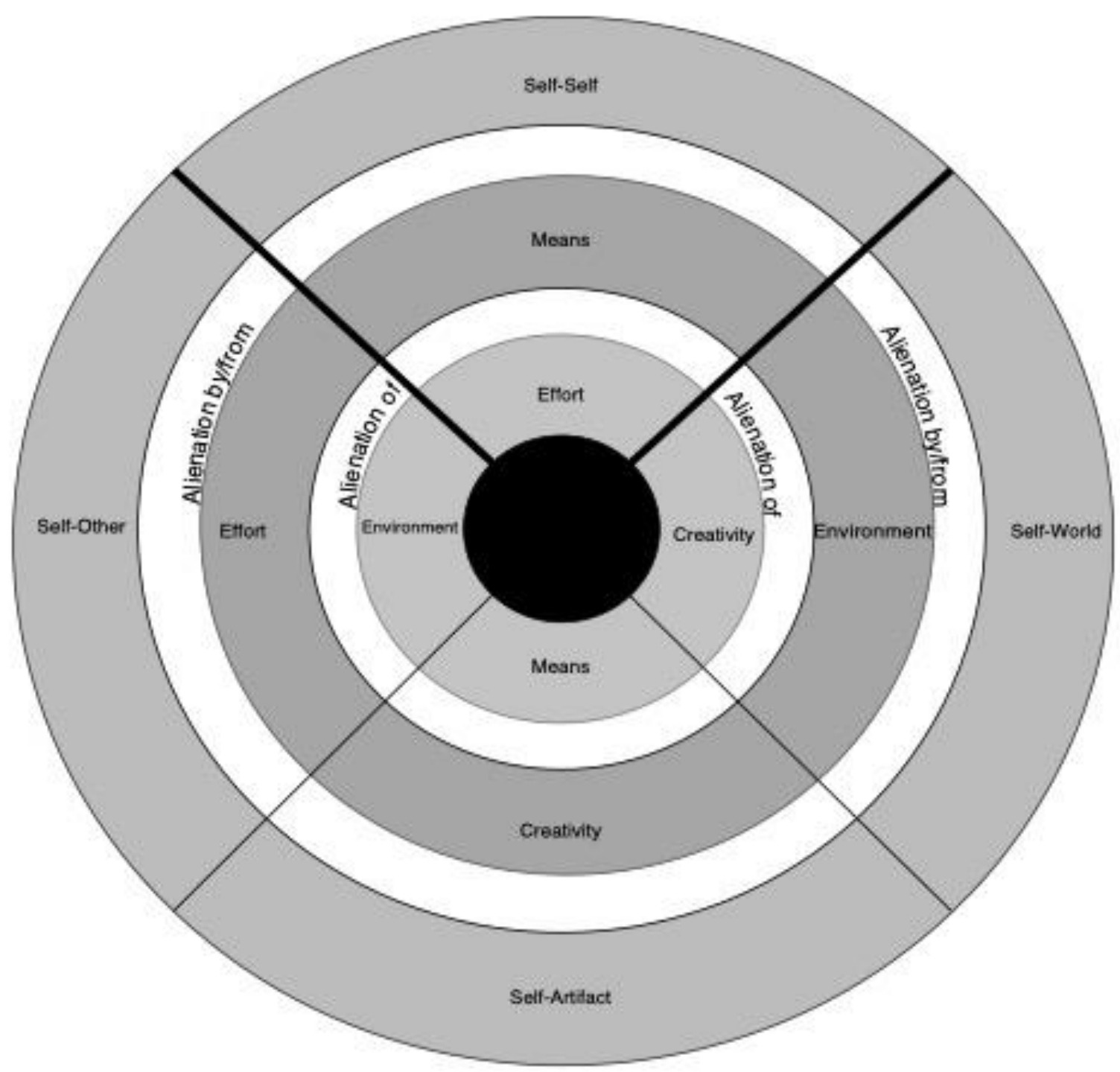

The Wheel of Alienation (I): The Level of General Action Theory

'The wheel of alienation' is a diagrammatic device for systematically organizing reflection and theoretical experimentation about how all of these aspects of alienation may interact. It provides a simple model that embodies the major principles outlined above: a complex array of forms of alienation may be derived and articulated, without giving conceptual priority to any specific form. This section introduces the 'wheel' and illustrates how to use it, 
without aiming to work through all of its implications exhaustively. That is, the goal here is to outline a generative theoretical model rather than to highlight any particular propositions we might draw from it.

Figure 1 shows the Wheel of Alienation in its most general form, and Figure 2 shows it specified to the sphere of production. The inner ring is the subject of alienation. The middle ring is the object of alienation. The outer ring is the relation of alienation. The dark lines focus attention on a specific configuration. For instance, Figure 1 highlights the alienation of effort from the means of action in the relation of the self to itself. Figure 2 highlights the same configuration, specified to the realm of production: the alienation of labor by capital in its productive activity. 


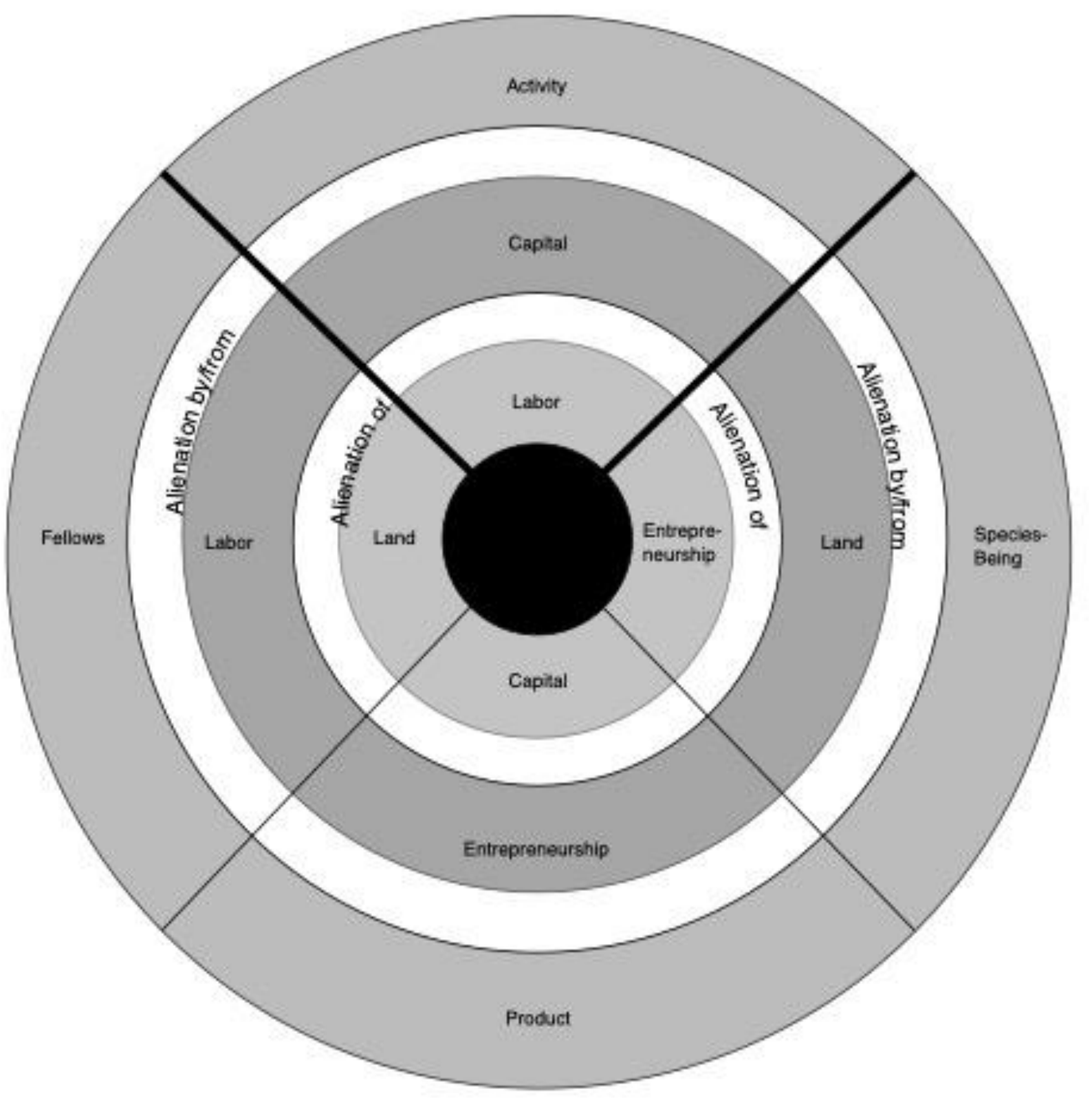

The Wheel of Alienation (II): The Sphere of Production

To work with this sort of diagram, one spins the various circles around, and observes the different configurations that result. Doing so helps to systematically elaborate and consider a range of possible alienations, without prioritizing any specific one. There is room here to examine the sorts of alienation that concerned Marx: Figure 1 and Figure 2 are positioned to 
highlight the alienation of labor specifically and effort more generally, for example. Spinning the outer ring cycles through the various aspects of alienation Marx imagined.

Yet the diagram also enables one to observe other configurations. In this way the wheel of alienation embodies the Simmelian impulse of pluralistic non-reductionism: alienation is always possible but never necessary, and once we abandon the essentialism of traditional alienation theory, there is no reason to assume a priori that labor is the only factor capable of being alienated. The point is not to deny that labor has been profoundly subject to alienation, but rather to indicate that this particular situation should not be baked into our theoretical framework from the start. A more open, formal, and multi-dimensional framework in fact allows us to pose more precise questions about when and why this configuration may have come to the fore, why it does or does not persist, and what other forms may emerge in different contexts. It permits alienation theory to retain its core principles while opening up to the problematics of the present. Working through some examples helps illustrate the theoretical utility of the wheel of alienation. Let us start with the alienation of effort. As we saw above, the alienation of effort involves indifference to cultivating and expanding capacities for action. Now consider indifference when the object of alienation (the middle ring) is 'means' and the relation of alienation is the self to itself (the outer ring). Here the self becomes indifferent to the personal significance of the tools it uses: a hammer or computer or iPhone become mere objects rather than opportunities for cultivating oneself according to one's own self-conception. In the sphere of production, this is the Marxian alienation of labor from its productive activity at the hands of the capitalist, where the process of work is not the worker's own. Spinning the outer ring invites consideration of a variety of indifferences: to others (indifference to how one's means deepen one's inter-personal interactions); to one's tools (indifference to the cultivation and refinement of 
tools that effectively channel one's energies outward), and to the world itself (indifference to how one's means contribute to the cultivation of a loving, facilitative environment).

Yet there are many other forms of indifference that may emerge, in the various ways that labor/effort may be alienated from means/capital but also from environment/land and creativity/entrepreneurship. The alienation of labor from land occurs when the energy one pours into one's work is severed from the environment in which one lives. One becomes indifferent to one's own situation, and its bearing on one's relation to oneself, others, one's artifacts, and the environment itself. An extreme example is commuting long hours to maintain the gardens of a gated community, but there are less extreme versions. In such situations, one's effort enhances somebody else's neighborhood and pulls one away from one's neighbors, severing productive activity from enhancing the community in which one lives. At the same time, and analogous to Marx's analysis of the dialectics of home and work when labor is alienated (Marx, 1978, p. 74), one's residential neighborhood becomes a zone of escape and retreat, rather than an environment for testing and growing one's productive abilities and benefiting from how they improve one's surrounds.

Labor and effort can also be alienated from the creative process, for example when the connection between the generation of ideas and their implementation is severed. Labor becomes a mere quantum of energy necessary to carry out ideas created somewhere else, and so becomes indifferent to the process of reconfiguring products and the social organization of work. The 'creatives' are over here, the laborers are over there, and the latter do not experience their activity as connected to the former. The hand is severed from the heart.

Labor is not the only factor of production capable of being alienated, however. Spinning the inner ring enables one to consider other possibilities: the alienation of 
creativity/entrepreneurship, environment/land, and even means/capital. Consider each briefly. The alienation of entrepreneurial creativity occurs when self and world become fixed in place and cease to be open fields of possibilities to be continually reconfigured and surpassed: reification. When creativity is dominated by capital (the middle ring), the creative process is not open to all possibilities. It is instead reified by the desire of owners to perpetually expand their operations, as when a designer's ability to play with ideas is constrained by the boss's judgments of their profitability. When creativity is dominated by land and the local environment, reification comes from not being permitted to imagine possibilities that might offend local customs and sensibilities or disturb the local character. When reification comes from domination of creativity by labor, new ideas are met by workers who are unwilling and unmotivated to devote energy to learning how to use or implement them. The proverbial peasant shovel is the result, a blunt tool frozen in time and not susceptible to adaptation or experimentation.

The alienation of our situatedness in place occurs when self and world become unmoored in and undefined by their place: disorientation. When places are dominated by capital, they become merely standing reserves of material resources and investment vehicles that provide no practical direction for cultivating oneself and others - a river is a power generator and nothing more, with no special status based on its place in a community's local practices or ways of life. Similarly, when the environment is dominated by entrepreneurship, it becomes fodder for interesting and novel experiments rather than sites of deep and abiding local traditions and customs that provide guidance for how to properly live a life - a street is there to be redesigned indiscriminately, without respect for its effect on personal or social growth. When labor predominates over place, the environment becomes simply a neutral place to work; work could be anywhere, and the fact that it is here but not there has no bearing on its value and significance: 
the stereotypical homogenous office park is the result. The needs and demands of the local area fail to provide concrete direction for guiding work toward cultivating relations to self and others that emerge out of their distinct local history and connections.

The alienation of the means of action occurs when they are blocked from expanding our abilities to control and direct ourselves and our environments: disempowerment. In the sphere of production, this is the alienation of capital, a phenomenon not contemplated by Marx but which the wheel of alienation encourages us to imagine. When capital is dominated by entrepreneurship, innovation devolves into tinkering and mere creative play, without resulting in the accumulation of tools that actually enhance the power to work more productively - the artistry of ideas outweighs their effectiveness and action loses its foothold in efficacy. When capital is dominated by labor, the process of accumulation is restricted by the labor pool, which in this scenario is unwilling to expand and redirect its efforts to work with larger accretions of capital. A specific form of disempowerment results: massive crystallization of potential productivity embodied in the factory or office stands ready to receive effort, but workers are unwilling to provide their energy to run them: they put their bodies upon the gears of the machine. When capital is dominated by land, the local environment restricts the process of accumulation and growth. Only certain areas are open to development, and the full set of powers that our environments could unleash are not unlocked. For action to be continually open to expanding its powers there must be some openness to the expansive potential of it means. But when disempowered in these ways, it becomes alienated from its own conditions of effectiveness.

These examples highlight primarily the implications of spinning the inner and middle rings, and how they produce multiple forms of indifference, reification, disorientation, and 
disempowerment. By spinning the outer wheel, we could refine these observations through systematically considering how indifference, reification, disorientation, and disempowerment occur across modes of self-world relationships. For instance, in the case of reification, this would involve reflecting on how it varies when the self takes itself as fixed and final; when it takes its relations to others to be unchangeable; when it takes its environment to be impervious to transformative action; and when it takes it tools to be eternal rather than provisional. In the present context, however, the primary point is more general: These illustrations of theoretical experiments performed upon the wheel of alienation indicate how the more familiar Marxian combinations are one specific configuration and that others even in the sphere of production may be contemplated.

Yet we may also use the wheel to ponder other possibilities. By aligning the inner and middle rings with themselves, we can consider forms of reflexive, self-destructive alienation more characteristic of the psychoanalytic tradition than the Marxian. Here we can examine entrepreneurial creativity that undermines itself, a hyper-creativity that produces so much change that it is impossible to distinguish new from old. Likewise we can consider the possibility of laborious effort spent attacking the ability to sustain effort: working hard to avoid hard work. Pursuing this latent theoretical potential in the wheel across permutations around the outer ring may facilitate further surprises and reflection upon the social processes in which action undermines itself.

Nor must we remain wedded to Marxian concepts of alienation embedded in Figure 2. The formal terms in Figure 1 are a bridge to other domains beyond production. For example, Simmel's Philosophy of Money treats money as the means of exchange par excellence, an 'absolute tool' capable of realizing the greatest range of desires. Money for Simmel thus 
becomes the ultimate medium for self-cultivation: 'Money grants to the self the most complete freedom to express itself in an object' (Simmel, 2005, p. 325). Yet as money expands the powers of the self to act and express itself in the world, it may also become the ultimate vehicle for disempowerment. 'This is precisely the miserly type - gaining satisfaction from having fully acquired potentialities without ever conceiving of their actualization' (Simmel, 2005, p. 325). Since money embodies a pure possibility to act, to spend it is to reduce one's power. Miserliness is the result.

In the terms of Figure 1, Simmelian miserliness is an example of the means of action undercutting the means to act so that the self becomes alienated from itself: the peak of reflexivity along this dimension, where 'means' is both subject and object of alienation in a 'selfself' relation. In a similar way, spinning the outer wheel so that 'self-other' aligns with 'means'

in both the inner rings reveals another characteristically Simmelian form of alienation, at least if we are considering the realm of money exchange. In this configuration, money becomes not a medium of connection and interaction but a 'prostitute' that 'signifies the nadir of human dignity (Simmel, 2005, p. 379): a means for manipulating relationships with others. Myriad other conceptual experiments are possible. The wheel of alienation provides a tangible medium for pursuing them.

\section{Conclusion: a research agenda for alienation theory}

These examples provide only the barest sketches of the various forms of alienation. They are meant only to illustrate how to work with the wheel of alienation, not to in any way exhaust its potential. This diagram, like all theory diagrams, operates at the level of potentiality, not actuality (Stjernfelt, 2007): it envisions a set of relations that permit us to map the contours of a 
space of possibilities. In this case, it is a diagram with which various interlocking configurations of the subjects, objects, and relations of alienation may be imagined, without granting a priori normative or conceptual priority to any particular constellation.

The value of this sort of diagram is in producing generative theoretical models to organize a research agenda. The wheel of alienation can provide alienation theory with a clear direction forward. As a first step, a much more thorough and systematic articulation of all potential forms of alienation is necessary. We need conceptual investigations of the various ways one can spin the wheels. These investigations would be pure social theory, not restrained by empirical likelihood. Drawing on art, literature, history, journalism, and one's own imagination, one builds rich portraits of what every possible configuration of alienation would be like, should it occur - even if it never has and perhaps never will. The second step is to elaborate propositions about when, where, and why particular configurations ought to in fact occur. For instance, we might hypothesize that in moments and areas of rapid industrial growth where capital is ascendant, the alienation of labor, land, and entrepreneurship at the hands of capital should be particularly acute. By the same token, when place and locale become crucial focal points of work, the alienation of other factors from and by land may be strong. These are some of the simplest propositions one might develop, but many other more complex formulations are possible. A third step is to expand the theoretical scope from the sphere of production to other domains, such as politics and culture. The present essay started with Marx and built outward, and so took production as its point of departure, while making some gestures toward exchange. But similar processes may occur in political and cultural alienation. It is an open theoretical question whether this four-factor model can illuminate alienation in these and other arenas. Articulating possibilities, expanding the scope, and formulating propositions constitute 
the core theoretical part of the agenda opened up by this paper. There are also major

methodological challenges, most notably in the accurate measurement of alienation. How to deal with these challenges is a difficult and open question, and there is much to be learned from the controversies and solutions developed in the last wave of alienation research. But to even raise such methodological questions again, the social theoretical imagination needs to be reawakened to the problem of alienation and given a coherent, generative analytical model to work with.

${ }^{1}$ The author wishes to thank Mark Alznauer, Milos Brocic, and Erik Schneiderhan for their helpful comments on earlier drafts of this paper, as well as participants in the 2016 conference of the ISA Research Committee on Sociological Theory.

${ }^{2}$ Writing in 1959, Daniel Bell noted that the wave of enthusiasm building for alienation studies at the time was itself a rediscovery of a concept that a previous generation had ignored. 3 Jaeggi (2014) also notes clear parallels with pragmatism, which are worth pursuing further, some of which are explored in Schwalbe (1992).

${ }^{4}$ I apply general Simmelian theoretical principles to more Marxian concepts, generally bracketing Simmel's specific application of his concepts to money (for this, see Silver and O’Neill 2014).

${ }^{5}$ Marx's notion of species being is clearly the most enigmatic and controversial. My (pragmatist inspired) reformulation as a facilitative environment is broadly in line with the suggestions of Dyer-Witheford (2008)

${ }^{6}$ Jäger 2003 reviews much of the Marxian literature on land and rent, as does Emsley 1998 (in pursuing the difficult distinction between 'absolute' and 'differential' rent). See also Harvey (2009).

${ }^{7}$ And for his part Marx certainly does strike pragmatist notes of creativity and growth, as many commentators have observed.

${ }^{8}$ Levine and Silver 2010 provide a fuller development of this interpretation of Simmel's vitalism. 


\section{References}

Alexander, J. C. (2006). The civil sphere. Oxford University Press.

Arditi, J. (1996). Simmel's Theory of Alienation and the Decline of the Nonrational. Sociological theory, 14, 93108.

Baudrillard, J. (1994) Simulacra and Simulation. Ann Arbor: University of Michigan Press.

Baldamus, W. (1976). The structure of sociological inference. M. Robertson.

Baldamus, W. (2013). Efficiency and effort: An analysis of industrial administration. Routledge.

Bell, D. (1959). 'The 'Rediscovery' of Alienation: Some Notes along the Quest for the Historical Marx,' The Journal of Philosophy Vol. 56, No. 24, pp. 933-952 .

Bell, D. (1976). The Coming of Post-industrial Society. A Venture in Social Forecasting. With a New Introd. by the Author. Basic Books Incorporated.

Callinicos, A. (2006) The Resources of Critique. London: Polity Press.

Camic, C., \& Joas, H. (2004). The dialogical turn. Bowman and Littlefield.

Crawford, Matthew B. (2009). Shop class as soulcraft: An inquiry into the value of work. Penguin.

Currid, E. (2007). The Warhol economy: how fashion, art, and music drive New York City. Princeton University Press.

Milà, N. C. (2015). A sociological theory of value: Georg Simmel's sociological relationism. transcript Verlag.

Castells, M. (1996) The Rise of Network Society: Economy, Society and Culture. London: Wiley Blackwell.

Debord, G. (1994). The society of the spectacle, trans. Donald Nicholson-Smith. New York: Zone Books, 12, 24-25.

Dyer-Witheford, N. (2008, November). Species-Beings: For Biocommunism. In Historical Materialism Conference, 'Many Marxisms. 'London School of Oriental and African Studies.

Emirbayer, M. (1997). Manifesto for a relational sociology. American journal of sociology, 103(2), 281-317.

Erikson, K. (1986). On work and alienation. American Sociological Review, 51(1), 1-8.

Fischer, C. S. (1976). Alienation: trying to bridge the chasm. The British journal of sociology, 27(1), 35-49.

Florida, Richard. The rise of the creative class. New York: Basic books, 2004.

Fuchs, S. (2009). Against essentialism: A theory of culture and society. Harvard University Press.

Gardiner, M. E., \& Haladyn, J. J. (Eds.). (2016). Boredom Studies Reader: Frameworks and Perspectives. Routledge.

Gee, J. M. A. (1981). The origin of rent in Adam Smith's Wealth of Nations: an anti-neoclassical view. History of Political Economy, 13(1), 01-18. 
Geyer, Felix and David Schweitzer. 1981. Alienation: problems of meaning, theory, and method. London: Routledge \& Kegan Paul.

Geyer, R. F., \& Heinz, W. R. (Eds.). (1992). Alienation, society, and the individual: Continuity and change in theory and research (Vol. 11, No. 6-8). Transaction Publishers.

Glaeser, E. (2011). Triumph of the city: How our greatest invention makes us richer, smarter, greener, healthier, and happier. Penguin.

Guppy, N., \& Davies, S. (1999). Understanding Canadians' declining confidence in public education. Canadian Journal of Education/Revue canadienne de l'education, 265-280.

Harvey, D. L., Warner, L. G., Smith, L., \& Harvey, E. S. (1983). Critical analysis of Seeman's concept of alienation. Humboldt Journal of Social Relations, 16-52.

Howard, M. C. and King, J. E. (1985). The Political Economy of Marx, New York, Longman Inc.

Israel, J. (1971) Alienation: From Marx to Modern Sociology. Boston, MA: Allyn \& Bacon.

Jaeggi, R. 2014. Alienation. New York: Columbia University Press.

Kolakowski, L. 1978. Main currents of Marxism, v. 1. Oxford: Clarendon Press.

Lackman, C. L. (1976). The classical base of modern rent theory. American Journal of Economics and Sociology, 287-300.

Langman, Lauren 2004. 'Globalization and the Liminal: Transgression, Identity and the Urban Primitive,' in Terry Clark Ed., The City as Entertainment Machine, Vol. 9 of Research in Urban Policy. New York: JAI Press/Elsevier

Langman, L., \& Kalekin-Fishman, D. (2009). Alienation: critique and alternative futures. Teoksessa Ann Denis \& Devorah Kaleikin-Fischer (eds.): The ISA Handbook of Sociology. London: Sage, 9-28.

Langman, L., \& Kalekin-Fishman, D. (Eds.). (2006). The evolution of alienation: Trauma, promise, and the millennium. Rowman \& Littlefield.

Lear, J. (1990). Love and its place in nature: A philosophical interpretation of Freudian psychoanalysis. Yale University Press.

Levine, D.N., 2004 'Simmel's Contradictory Formulations Regarding the Crisis of Modern Culture,' Culture and Society 5 (2004).

Levine, D.N. 2008. 'Simmel's Shifting Formulations Regarding the Antinomies of Modern Culture,' Simmel Studies 18, No. 2: 239-63.

Levine, D.N. and Daniel Silver. 2010. 'Introduction,' in Simmel, G., Levine, D. N., \& Andrews, J. A. The View of Life: Four Metaphysical Essays with Journal Aphorisms. University of Chicago Press.

Levine, D. N. (1995). Visions of the sociological tradition. Chicago: University of Chicago Press.

Lefebvre, H. (1968) Dialectical Materialism. London: Cape.

Logan, John R., and Harvey Molotch. Urban fortunes: The political economy of place. Univ of California Press, 2007. 
Marshall, Alfred. Principles of Economics Vol. I. New York: MacMillan and Co., 1892.

Markusen, A. (2006). Urban development and the politics of a creative class: evidence from a study of artists. Environment and planning A, 38(10), 1921-1940.

Marx, Karl (1959). 'Economic and Philosophical Manuscripts of 1844,' tr. Martin Mulligan, Moscow: Progress Publishers, https://www.marxists.org/archive/marx/works/download/pdf/Economic-Philosophic-Manuscripts1844.pdf

Marx, Karl. [1867-1894 (1967)]. Capital, New York, International Publishers, Vols. I-III.

Mei, T. (2017). Land and the Given Economy: An Essay in the Hermeneutics and Phenomenology of Dwelling. Northwestern University Press.

Moretti, E. (2012). The new geography of jobs. Houghton Mifflin Harcourt.

Ollman, B. (1976) Alienation: Marx's Conception of Man in Capitalist Society, $2^{\text {nd }}$ edn. Cambridge: Cambridge University Press.

Oldenquist, Andrew. 'Autonomy, social identities, and alienation,' in in Alienation, Society and the Individual, eds. Felix Geyer and Walter Heniz, New Brunswick and London: Transaction Publishers, pp. 53-60.

Parsons, T., \& Smelser, N. (2005). Economy and society: A study in the integration of economic and social theory. Routledge.

Parsons, Talcott. 1967. 'Some Comments on the Sociology of Karl Marx,' in Sociological Theory and Modern Society. New York: The Free Press.

Parsons, Talcott. 1949. The Structure of Social Action: A Study in Social Theory with Special Reference to a Group of Recent European Writers, 2nd edition. Glencoe, IL: Free Press.

Poggi, Gianfranco. 1993. Money and the Modern Mind: Georg Simmel's Philosophy of Money. Chicago:

University of Chicago Press.

Reich, R. B. (2002). The future of success: Working and living in the new economy. Vintage.

Relph, Edward. 2008. Place and Placelessness. London: Pion.

Rae, G. (2010). Alienation, authenticity and the self. History of the human sciences, 23(4), 21-36.

Rognlie, Matthew (2014) A Note on Piketty and Diminishing Returns to Capital http://www.mit.edu/ mrognlie/piketty diminishing returns.pdf.

Sampson, Robert. 2012. Great American City. Chicago: University of Chicago Press.

Schacht, R. (1971) Alienation. St Leonards, Sx: Allen \& Unwin.

Schacht, R. (1994) The Future of Alienation. Chicago, IL: University of Illinois Press.

Schwalbe, Michael. 1992. 'Alienation as the Denial of Aesthetic Experience,' in Alienation, Society and the Individual, eds. Felix Geyer and Walter Heniz, New Brunswick and London: Transaction Publishers, pp. 91-106.

Seeman, M. (1959) 'On the Meaning of Alienation', American Sociological Review 24: 783-91. 
Seeman, M. (1967) 'On the Personal Consequences of Alienation in Work', American Sociological Review 32(2): 273-85.

Seeman, M. (1975) 'Alienation Studies', Annual Review of Sociology 1: 91-123.

Seeman, M. (1983) 'Alienation Motifs in Contemporary Theorizing: The Hidden Continuity of the Classic Themes', Social Psychology Quarterly 46(3): 171-84.

Sennett, R. (2011). The corrosion of character: The personal consequences of work in the new capitalism. WW Norton \& Company.

Silver, D. and O’Neill K. (2014). 'The significance of religious imagery in The Philosophy of Money: Money and the transcendent character of life.' European Journal of Social Theory, 17 (4) 389-406

Simmel, G., Levine, D. N., \& Andrews, J. A. (2010). The View of Life: Four Metaphysical Essays with Journal Aphorisms. University of Chicago Press.

Stjernfelt, F. (2007). Diagrammatology: An investigation on the borderlines of phenomenology, ontology, and semiotics (Vol. 336). Springer Science \& Business Media.

Strangleman, T. (2005) 'Sociological Futures and the Sociology of Work', Sociological Research Online, 10(4), available online at: http://www.socresonline.org.uk/10/4/strangleman.ht

Urry, J. (2000) Sociology beyond Societies: Mobilities for the Twenty-First Century.London: Routledge.

Ward, C. and Aalbers, M.B. (2016) 'The shitty rent business': What's the point of

land rent theory? Urban Studies 53 